\title{
ANÁLISE DE RISCO DO DESENVOLVIMENTO DA SÍNDROME DE BURNOUT EM ATLETAS ADOLESCENTES DE HANDEBOL
}

${ }^{1}$ Francine Paula Gomes Banhos

${ }^{2}$ Clóvis Marcelo Sedorko

\section{RESUMO}

Introdução: A Síndrome de Burnout (SB) se configura em uma exaustão psicofísiológica, a qual pode acometer atletas que sofrem com o excesso de cobranças e alta intensidade de treinamento. Objetivo: O referido estudo apresentou o objetivo de identificar possíveis riscos para o surgimento da SB junto a atletas adolescentes praticantes da modalidade esportiva Handebol. Método: Esta pesquisa de cunho qualitativo foi desenvolvida em uma instituição particular de ensino do município de Ponta Grossa/PR e a amostra foi composta por 14 adolescentes do sexo feminino. Resultados e discussão: Os resultados evidenciam que as referidas atletas apresentam risco baixo de desenvolver a Síndrome de Burnout. Conclusão: Observa-se a importância dos professores e treinadores estarem atentos as consequências decorrentes da SB e na eventualidade de algum atleta apresentar sintomas dessa síndrome, ressalta-se a necessidade do devido acompanhamento psicológico para realizar o tratamento necessário.

Palavras-chave: Burnout, Atleta, Exaustão.

\section{RISK ANALYSIS OF THE DEVELOPMENT OF BURNOUT SYNDROME IN ADOLESCENT HANDBALL ATHLETES}

\section{ABSTRACT}

Introduction: The Burnout Syndrome (SB) is configured in a psychophysiological exhaustion, which can affect athletes who suffer from excessive demands and high training intensity. Objective: The aforementioned study had the objective of identifying possible risks for the appearance of BS with adolescent athletes who practice the handball sport modality. Method: This qualitative research was developed in a private educational institution in the city of Ponta Grossa / PR and the sample was composed of 14 female adolescents. Results and discussion: The results show that these athletes are at low risk of developing burnout Syndrome. Conclusion: It is observed the importance of teachers and coaches to be aware of the consequences arising from the BS and, in the event of an athlete presenting symptoms of this syndrome, the need for proper psychological monitoring to carry out the necessary treatment is highlighted.

Keywords: Burnout, Athlete, Exhaustion.

\footnotetext{
${ }^{1}$ francinebanhos@outlook.com

2prof.clovis@iessa.edu.br
} 


\section{INTRODUÇÃO}

A saúde mental dos desportistas pode interferir no rendimento e comportamento do atleta, o que torna este um assunto importante na área da Educação Física. Os atletas que possuem uma boa saúde mental sabem enfrentar o estresse competitivo e possuem controle da concentração, da atenção e ainda apresentam melhorias na comunicação e no desenvolvimento da autonomia e liderança (RÚBIO, 2003).

Porém, quando esses indivíduos efetuam treinamentos com cargas e cobranças mais altas que o necessário, podem apresentar maior probabilidade de desenvolver a Síndrome de Burnout (SB), resultando no desequilíbrio da saúde mental e na consequente queda do rendimento atlético e até mesmo na desistência da prática competitiva, sobretudo nas fases de iniciação e de especialização do esporte, como o período da adolescência.

A SB pode ser definida como um distúrbio psíquico, oriundo do estresse ocupacional, ocasionando a exaustão emocional, a falta de energia e entusiasmo e a diminuição do desempenho (MASLACH, SCHAUFELI, LEITER, 2001 apud CARLLOTO, 2002, p. 23). A palavra burnout é uma junção do inglês "burn" e "out", que significa "queimar" e pode ser também considerado "esgotamento". Freudenberger foi o primeiro autor a descrever a Síndrome de Burnout em
1974, definindo burnout como cansaço físico e psicológico, causado por cobranças exageradas no ambiente de trabalho (FEJGIN, TALMOR, ERLICH, 2005 apud PIRES, BRANDÃO, SILVA, 2006, p. 27).

Segundo Silva (2010) apud Rocha e Santos (2014, p. 5-6) a SB apresenta alguns estágios conhecidos, entre os quais: a obrigação de autoafirmação; absoluta afeição; abnegação as obrigações pessoais fundamentais como: comer e dormir; indeferimento do problema; manifestações corporais como a fadiga; dano de valores sociais e familiares; valorização excessiva dos afazeres; desvalorização dos companheiros de trabalho; desaforo e violência são os sinais que mais se manifestam; recolhimento; modificações de comportamento; vazio interior; depressão; desvalorização da vida; e então o Burnout, que responde ao cansaço físico e mental no qual é considerado emergencial.

De acordo com Rudow (1999) apud Carlotto (2002, p. 23) a evolução do processo do Burnout pode demorar muitos anos sem que 0 indivíduo perceba que possui a síndrome, fato que notadamente trará malefícios no ambiente de trabalho.

Para Maslach, Schaufeli e Leiter, (2001) apud Carlotto (2002, p. 23-24), apesar de existirem várias definições da $\mathrm{SB}$, pode-se perceber a presença de cinco elementos comuns em todas elas: [...] 1) predominância de sintomas relacionados a exaustão mental e
emocional, fadiga e depressão; 2) a ênfase nos sintomas comportamentais
e mentais e não nos sintomas físicos; 3) os sintomas do burnout são
relacionados ao trabalho; 4) os sintomas manifestam-se em pessoas
"normais" que não sofriam de distúrbios psicopatológicos antes do
surgimento da síndrome; 5) a diminuição da efetividade e desempenho no
trabalho ocorre por causa de atitudes e comportamentos negativos
(MASLACH, SCHAUFELI, LEITER, 2001 apud CARLOTO, 2002, p. 23-24).

Conforme exposto na citação acima, dentre os fatores comuns inerentes a SB, observa-se a maior ênfase nos sintomas de ordem comportamental e mental e não necessariamente nos sintomas físicos, fato que requer maior atenção de professores e treinadores, essencialmente na formação de atletas. Outro aspecto observado diz respeito ao surgimento dos sintomas em pessoas consideradas normais, ou seja, aquelas que não apresentavam distúrbios de ordem psicológica antes de serem acometidas pela SB e diante dessa constatação, novamente ressalta-se a necessidade de tais profissionais estarem atentos aos sintomas e consequências decorrentes da SB.
Os esportes coletivos representam uma dificuldade maior para que o profissional do movimento perceba o desenvolvimento ou sintomas da síndrome nos atletas, devido à quantidade de integrantes da equipe. Em relação ao handebol, este esporte apresenta ainda a característica de ser um jogo com demasiado contato físico e elementos técnicos que precisam ser bem executados, para tanto, é essencial que os atletas desta modalidade esportiva tenham um bom desenvolvimento motor (ALTINI NETO, PELLEGRINOTTI, MONTEBELO, 2006), bem como o domínio satisfatório das habilidades básicas, como correr, saltar e arremessar, além de uma boa estrutura física e psíquica (RUIZ, EGOCHEAGA RODRÍGUEZ, 2001; ARPINI, VICENTINI, 2017). 
Tais condições podem ser alcançadas adolescência represente um desafio, visto que as rotinas de treinamento dos atletas devem ser conciliadas com outros afazeres e responsabilidades, como escola, família, vida social, etc. Nesse sentido, Marques Junior (2012) ressalta que os treinamentos inerentes à iniciação esportiva devem priorizar a qualidade em detrimento da quantidade de horas trabalhadas.

O período da adolescência é caracterizado pelo estirão de crescimento (FREIRE, SCAGLIA, 2003), portanto, é comum que muitos jovens apresentem eventuais dificuldades motrizes decorrentes desse crescimento corporal acelerado. Especificamente em relação ao sexo feminino, nota-se que o desenvolvimento corporal das meninas inicia-se por volta dos 10 anos, sendo aos 12 anos o pico de crescimento (MALINA et al., 2009; ROGOL et al., 2002; ROWLAND, 1996 apud RÉ, 2011, p. 62). A menarca vem logo após esse período, o que traz uma alteração da produção de hormônios, os quais não interferem significativamente no ganho da massa muscular, mas apresentam um aumento na quantidade de gordura corporal, especialmente nas áreas de busto e quadril (RÉ, 2011).

Segundo Ré (2011), o aumento da gordura corporal não acarreta em melhorias de execução das habilidades motoras, mas também não representa obrigatoriamente a queda do desempenho. $O$ fato a ser observado nesse contexto refere-se a eventuais malefícios para a autoestima decorrente dessa modificação corporal, que somados as instabilidades psicológicas e sociais inerentes ao período da adolescência pode influenciar negativamente no engajamento e permanência dessas jovens nas práticas competitivas.

\section{SÍNDROME DE BURNOUT NA ÁREA ESPORTIVA}

No tocante a Síndrome de Burnout na área esportiva, Pires et al., (2012, p. 132) ressaltam que a mesma começou a ser estudada a partir da década de 1980 e as primeiras pesquisas buscaram analisar as "diferenças de gênero na percepção da síndrome em treinadores esportivos". Nos anos seguintes foram empreendidos estudos visando à adaptação de conceitos do Burnout para o âmbito do esporte, visto que o sistema esportivo exige "diferentes estratégias de enfrentamento do forte componente emocional característico da síndrome (GARCÉS DE LOS FAYOS, 1999 apud
PIRES, BRANDÃO, SILVA, 2006 p. 28). As intensas demandas de treinamentos físicos e/ou técnicos e as competições apresentam correlação com a exaustão emocional e física dos atletas, ou seja, se o atleta treina com uma intensidade mais alta do que precisa, pode manifestar a síndrome de Burnout, resultando em estresse psicológico e físico, e consequentemente na queda no rendimento esportivo, culminando em alguns casos no abandono do esporte por falta de prazer e bem-estar (SILVÉRIO, 1995; CHIMINAZZO, MONTAGNER, 2004; PIRES et al., 2012; NUNES, 2009).

Para Samulski (2002 p. 349) a SB acarreta alguns sintomas como a perda do interesse pelo esporte, exaustão física e mental, falta de preocupação e aumento ou desenvolvimento da ansiedade e depressão. Comportamentos como mudanças de humor, afeto negativo, baixa autoestima, abuso de substâncias químicas (consumo de bebidas alcoólicas e tabagismo), distúrbio do sono, falta de preocupação, perda do desejo de jogar e problemas de concentração também podem ser observados nos indivíduos que são acometidos pela síndrome (HACKENEY et al., 1990 apud SAMULSKI, 2002 p. 352).

Atletas de ambos os sexos são propensos a adquirir a SB, sejam eles divorciados, solteiros ou viúvos, sendo que indivíduos do sexo masculino podem apresentar ruptura da personalidade, enquanto que atletas do sexo feminino tendem a manifestar uma exaustão emocional maior (BURKE, 1989; MASLACH et al., 2001; NAGY, DAVIS, 1985; RAQUEPAW, 1989 apud TRIGO, TENG, HALLAK, 2007, p. 227). De acordo com Smith (1986) apud Pires et al., (2012, p. 132) a SB é mais comum em desportistas de modalidades individuais, devido a fatores como a maior exigência psicológica e física dos atletas, ao fato de ser mais competitivo e em razão do baixo apoio social dos companheiros de treino, o qual caracteriza-se pela repetição e monotonia, diferentemente do que ocorre em modalidades coletivas.

Considerando os malefícios causados pela SB nos desportistas, ressalta-se a importância do treinamento adequado, mediante apoio emocional e afetivo por parte dos treinadores e profissionais da área, bem como pela variação de metodologias e distribuição de cargas e intensidades compatíveis com os princípios do treinamento desportivo. 
Análise de risco de Burnout em adolescentes praticantes de handebol

\section{FASES PARA O BURNOUT: ESTRESSE E OVERTRAINING}

A síndrome de Burnout é frequentemente confundida com o overtraining e o estresse, tendo cada uma suas diferenças e peculiaridades.

O estresse no esporte está presente em competições, no medo do fracasso, e cobranças de treinadores e familiares, o que pode causar um desencadeamento em respostas físicas e psicológicas em busca da homeostase. McGrath (1976) apud Brandão, (2000, p. 120-121) descreve quatro fases do estresse: Demanda Ambiental, o desportista encontra-se em um momento ameaçador; Percepção da Demanda Ambiental, após o desportista reconhecer a situação, ele realiza uma autoavaliação podendo avaliar a situação como ameaçadora; Respostas Físicas e Psicológicas do Estresse, após perceber a ameaça, o atleta pode apresentar dois tipos de respostas (sintomas biológicos, como o aumento dos batimentos cardíacos e psicológicos, como a ansiedade); Consequências Comportamentais, esse estágio pode apresentar consequências positivas e negativas. Se o atleta supera a situação estressora, torna a performance positiva e essa ação pode ser chamada de "estresse positivo" ou "eustresse". Se o estresse causar dano ao desempenho do desportista, é denominado de "estresse negativo" ou "distresse".

O overtraning, conhecido também como síndrome do excesso de treinamento (ROHLFS et al., 2005), é um distúrbio neuroendócrino que causa um desequilíbrio do processo do exercício e a assimilação de treinamento, ocasionando alterações metabólicas que trazem malefícios nos aspectos fisiológicos e emocionais e, consequentemente prejudicam o desempenho. Quando a carga do treino é intensa e ultrapassa a capacidade de recuperação e adaptação, o organismo do atleta causa mais a quebra de moléculas complexas (catabolismo) do que a construção das mesmas (anabolismo) (WILMORE, COSTILL, 2001).

Para detecção do overtraining, existem 4 fatores que os atletas apresentam e que devem ser levados em consideração: Fisiológico, obtém a diminuição da força muscular e alteração do nível de lactato; Bioquímicos, provoca a diminuição do glicogênio muscular e da mineração óssea; Psicológico, como o estresse emocional e apatia geral; Imunológico, aumento da infecção e enfermidades (FRY, MORTON, KEAST, 1991 apud CUNHA, RIBEIRO, OLIVEIRA, 2006, p. 298).

Dessa forma, o atleta inicia o processo passando pelo estresse causado pela situação momentânea no cenário esportivo, evoluindo para o overtraining, no qual começa a experimentar dificuldades no desempenho, e por fim manifesta o Burnout, em que o aparato psicofísico do atleta começa a ter respostas negativas, entre as quais a exaustão emocional e até mesmo o abandono do esporte.

A exaustão emocional apresenta correlação com enfermidades como: ansiedade, tensão física e psicológica, dores na cervical e lombar, sensação de diminuição de energia, raiva, redução de empatia e a impaciência, as quais por sua vez interferem no rendimento e bem-estar do atleta (CHERNISS, 1980 apud TRIGO, TENG, HALLAK, 2007 p. 225).

Quando um atleta se sente insatisfeito com suas habilidades e desempenho, ele apresenta um senso de realização esportiva baixa (RAEDEKE, SMITH, 2001 apud PIRES, SOUZA, CRUZ, 2010), desse modo, faz-se necessário que os profissionais envolvidos com a formação de atletas adotem estratégias de treinamento e orientação adequadas, no intuito de motivar esses indivíduos, reduzindo assim os sentimentos negativos $e$ a indesejável manifestação da SB, a qual apresenta associação com a desistência esportiva.

Nesse contexto, esta pesquisa apresentou o objetivo de identificar possíveis riscos para o surgimento da Síndrome de Burnout junto a atletas em idade escolar de um colégio particular do município de Ponta Grossa/PR, visando ampliar as reflexões acadêmicas sobre as metodologias de treinamento esportivo, sobretudo com atletas em formação.

\section{MÉTODO}

Essa pesquisa foi desenvolvida mediante uma abordagem de cunho qualitativo (MARCONI, LAKATOS, 2004), em um colégio particular do município de Ponta Grossa, Paraná. Em um primeiro momento, a referida instituição de ensino foi contatada e informada sobre os objetivos desta pesquisa e após o entendimento e autorização dos responsáveis, concedida por meio do T. A. I. (Termo de Autorização Institucional), iniciou-se 0 


\section{Análise de risco de Burnout em adolescentes praticantes de handebol}

processo de regulamentação junto ao CEP (Comitê de Ética) da Faculdade Santana/Plataforma Brasil, cuja aprovação deu-se por meio do parecer de número 3.498.730.

A pesquisa foi realizada com 14 atletas do sexo feminino da modalidade de handebol de um colégio particular de Ponta Grossa, Paraná, pertencentes às categorias sub 14 e sub 17, dentre uma faixa etária de 13 a 17 anos. As atletas iniciaram sua vida esportiva na modalidade indicada aos 10 anos de idade, não se dedicando apenas a carreira esportiva, mas também aos trabalhos e estudo.

As atletas treinavam 3 vezes por semana, com duração de uma hora e trinta minutos, possuindo uma rotina com viagens aos fins de semana para os jogos das fases escolares. Essas atletas foram informadas acerca dos objetivos deste trabalho acadêmico após aprovação dos responsáveis pela instituição na qual estudam e receberam todos os esclarecimentos referentes aos objetivos da pesquisa e particularidades sobre 0 instrumento de coleta de dados.

Para obtenção dos dados utilizou-se como instrumento um questionário "Questionário de Burnout para Atletas" (QBA)

\section{RESULTADOS e DISCUSSÃO}

O questionário foi respondido por 14 atletas adolescentes. Em relação à alta intensidade de treinos e cobranças, quando questionadas sobre a categoria Exaustão Física e Emocional, expõe-se no gráfico 1 que validado por Pires, Brandão e Silva (2006), o qual foi respondido pelas adolescentes após a prévia autorização de seus respectivos responsáveis, obtida por meio do Termo de Consentimento Livre e Esclarecido (TCLE) e do Termo de Assentimento.

O QBA possui 15 perguntas e cada uma dessas perguntas possui uma categoria, sendo elas: exaustão física e emocional, reduzido do senso de realização esportiva e desvalorização esportiva. As respostas nos questionários são objetivas: 1 (quase nunca), 2 (raramente), 3 (algumas vezes), 4 (frequentemente) e 5 (quase sempre). A análise dos dados foi empreendida a partir da média aritmética das respostas dadas aos cinco itens de cada pergunta do instrumento (questionário) e o valor de Burnout total foi obtido pelo cálculo da média aritmética de todos os quinze itens do instrumento de pesquisa. A interpretação dos pontos foi realizada com a utilização da variação de frequência de sentimentos.

De acordo com Pires, Brandão e Silva (2006), existe um índice satisfatório de confiabilidade para o QBA, onde o mínimo é de $70 \%$, assim, nesta pesquisa obteve-se o índice de $75 \%$ de confiabilidade das análises individuais.

$64 \%$ das atletas indicaram a opção "quase nunca". A opção "raramente" foi apontada por $29 \%$ das entrevistadas e o termo "algumas vezes" obteve $7 \%$ das indicações. As opções "quase sempre" e "frequentemente" não foram marcadas por nenhuma atleta.

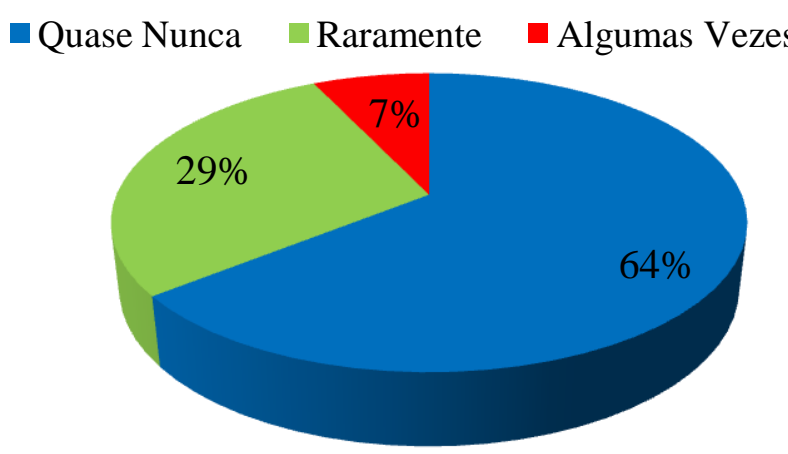

Gráfico 1: Respostas da Categoria "Exaustão Física e Emocional”.

A rotina de treino dos adolescentes que participaram da pesquisa são treinamentos de uma hora e meia, três vezes por semana, não sendo caracterizado como exaustivo e pesado, e durante esse período há intervalos de 48 horas. Essa categoria está ligada ao sentimento de sobrecarga, sendo a que mais se aproxima do estresse.

está descansado fisicamente e
Indica-se que o tempo de descanso após o período de treinamento é no mínimo de seis horas a vinte e quatro horas. Em período de competições, o ideal seria de vinte e quatro horas á setenta e duas horas de descanso. Os treinos para melhor rendimento devem ser realizados no período da manhã, pois o atleta 
Análise de risco de Burnout em adolescentes praticantes de handebol

intelectualmente (MONTEIRO, 2002, VILLAR, 1987; JENSEN et al., 1997 apud MARQUES JUNIOR, 2012).

Segundo Cherniss (1980) apud Trigo, Teng e Hallak (2007 p. 225) a exaustão física e emocional pode desencadear muitos problemas, entre os quais: a diminuição da empatia, raiva, impaciência, tensão muscular e distúrbios do sono. Em relação ao resultado obtido nesta pesquisa no tocante à categoria Exaustão Física e Emocional, observa-se que os profissionais do colégio responsáveis pelo treinamento, desenvolvem o mesmo em conformidade com os preceitos e indicações acadêmicas da área do treinamento desportivo, respeitando o tempo de descanso e recuperação, fato que traz benefícios para as atletas, como a ausência da exaustão física e emocional.

Sobre a categoria de Reduzido Senso de Realização Esportiva (insatisfação e destreza no desporto), observa-se no gráfico 2 que a alternativa "raramente" foi apontada por $64 \%$ das atletas. Já o termo "algumas vezes" apresentou percentual de $36 \%$. As alternativas "quase nunca", "frequentemente" e "quase sempre" não foram marcadas pelas atletas.

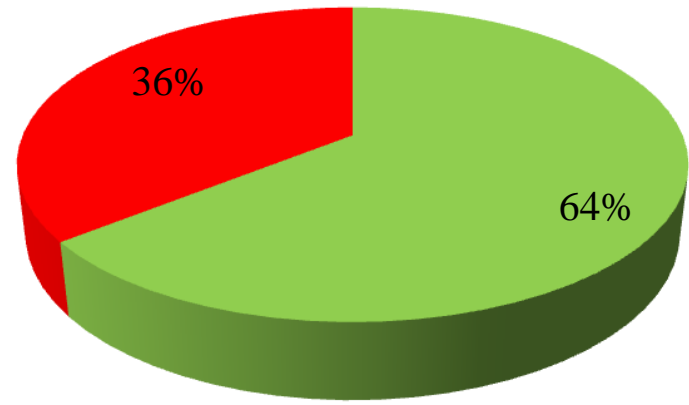

Raramente

- Algumas Vezes

Gráfico 2: Respostas da Categoria de "Reduzido Senso de Realização Esportiva".

Segundo Nunes (2009) a SB pode ser desencadeada como consequência do estresse e cobranças excessivas, gerando queda no rendimento do atleta e por sua vez a impossibilidade de alcançar as metas propostas pelo treinador, fato que só faz aumentar a tensão sobre o indivíduo e em alguns casos a desistência do esporte. As rotinas de treinamentos e competições e as situações de tensão inerentes ao desporto convencional tendem a ocasionar instabilidades emocionais junto aos atletas, nesse sentido, é essencial que o treinador busque motivar a equipe, adotando estratégias que facilitem 0 enfrentamento do estresse competitivo (RUBIO, 2003).

Conforme preconizam Raedeke e Smith (2001) apud Pires, Souza e Cruz (2010, p. 39) o senso de realização esportiva tende a ser baixo nas situações em que o atleta demonstra insatisfação com suas habilidades e desempenho. No caso do handebol é particularmente necessário 0 domínio das habilidades físicas e técnicas bem como da estrutura psíquica e mental (RUIZ, EGOCHEAGA RODRÍGUEZ, 2001; ALTINI NETO, PELLEGRINOTTI, MONTEBELO, 2006; ARPINI, VICENTINI, 2017). No entanto, os dados obtidos nesse quesito evidenciam que as atletas de handebol participantes desta pesquisa apresentam um nível de baixo para mediano de Reduzido Senso de Realização Esportiva, na qual raramente avalia-se que não possuem habilidades e/ou capacidades para a prática da referida modalidade.

Os resultados evidenciados no gráfico 3 referem-se a categoria Desvalorização Esportiva (à falta de interesse pelo esporte), sendo aquela que traz pouca ou nenhuma preocupação com o rendimento desportivo. Os dados obtidos revelam um percentual de $50 \%$ na escala "quase nunca", $7,1 \%$ "raramente", $28,6 \%$ "algumas vezes", 14,3\% "frequentemente" enquanto que a escala "quase sempre" não foi indicada. 


\section{Análise de risco de Burnout em adolescentes praticantes de handebol}

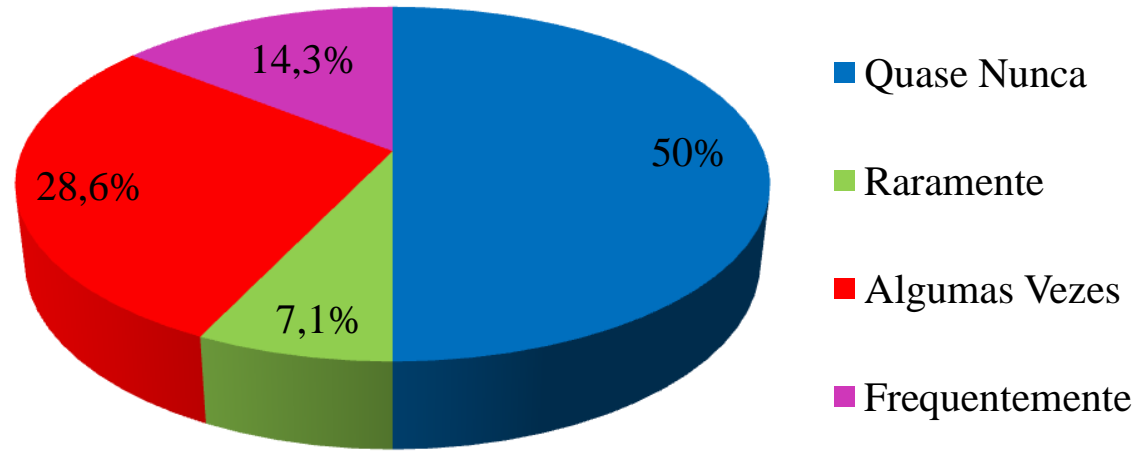

Gráfico 3: Respostas da Categoria de "Desvalorização Esportiva".

Observa-se que os atletas na categoria supracitada apontaram um índice maior na escala "frequentemente" em relação às outras categorias. Pires, Souza e Cruz (2010) ressaltam que quando um atleta deixa de demonstrar preocupação com seu desempenho e envolvimento no contexto desportivo, inicia-se um processo associado a desvalorização esportiva, ocasionando a falta de interesse e desejo em relação ao esporte.

Nas situações em que o conjunto de hábitos de cunho social (estudo e trabalho) for incompatível com as atribuições da vida esportiva (treinamentos e competições) podese causar um confronto negativo entre essas tarefas, trazendo malefícios para o bem-estar psicológico, como a tensão, a raiva, e o aumento da ansiedade e da probabilidade de comportamentos depressivos (SAMULSKI, 2002). Diante desse quadro, presume-se que uma eventual desarmonia no estilo de vida das atletas de handebol possa ter exercido alguma influência no resultado desta categoria, portanto, destaca-se a necessidade de constante monitoramento das questões comportamentais apresentadas pelos jovens envolvidos com o esporte. Segundo Rubio (2019) faz-se necessário compreender as particularidades desse fenômeno para que seja possível oferecer os devidos recursos visando a superação dos problemas e especificidades encontradas.

$\mathrm{Em}$ relação às atletas que responderam os itens "algumas vezes" e "frequentemente" na categoria de Desvalorização Esportiva, supõe-se que as mesmas sejam reservas e estejam em fase final escolar. Estas possuem cobranças para o futuro profissional, o que pode ocasionar a um confronto negativo entre a vida social e a vida esportiva.

Para auxiliar as referidas atletas a conciliar essas demandas acredita-se ser importante o constante trabalho motivacional por parte dos professores e treinadores, com ênfase na melhoria da autoestima, otimismo e autocontrole. Nesse sentido, Bara Filho, Ribeiro e Miranda (1999, p. 77) entendem que o técnico deve também trabalhar de maneira variada, fugindo da monotonia e fazendo atividades diferentes que possam chamar a atenção das atletas.

O gráfico 4 mostra a média geral de todas as categorias e de todas as atletas. Nota-se que as atletas da modalidade de handebol, em geral possuem 0 resultado elevado na alternativa "quase nunca" na média das três categorias, desse modo, entende-se que as atletas apresentam probabilidade muito reduzida de desenvolver a SB. 


\section{Análise de risco de Burnout em adolescentes praticantes de handebol}

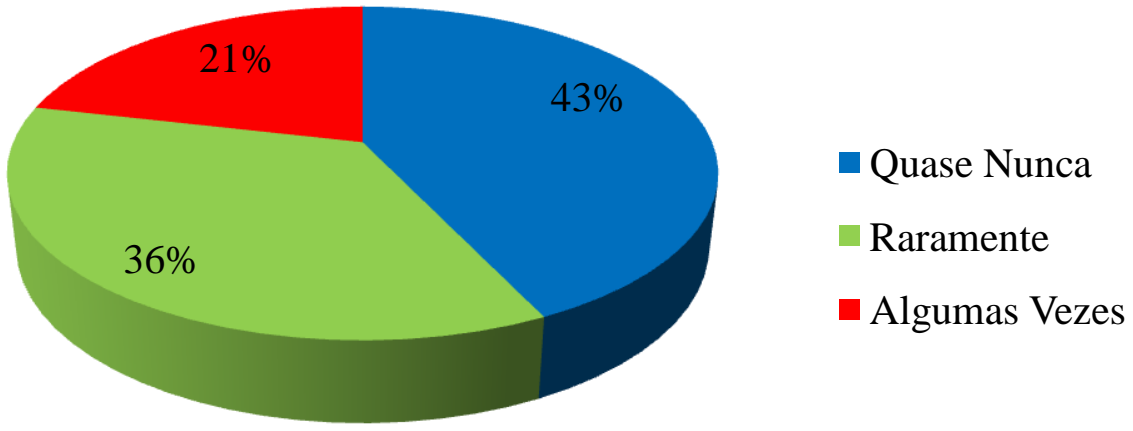

Gráfico 4: Média Total das Categorias.

Smith (1986) apud Chiminazzo e Montagner (2004, p. 4) afirma que nas modalidades esportivas coletivas é mais difícil notar a presença de Burnout, pois estes esportes apresentam divisão de tarefas, bem como relações interpessoais nas equipes. Observa-se que nos esportes de equipes os treinos são considerados menos repetitivos, tendo mais ludicidade, possuindo apoio entre os colegas do time e assim diminuindo a probabilidade do surgimento do Burnout. No estudo de Silvério (1995) constatou-se que atletas de modalidades individuais como atletismo, natação e ciclismo apresentam maior vulnerabilidade a situações de Burnout na comparação com triatletas que realizam essas mesmas modalidades, devido a menor complexidade observada na prática isolada destes desportos.

Smith (1986) apud Pires et al., (2012, p. 132) da mesma forma evidencia que a ocorrência da SB é mais recorrente em atletas de modalidades individuais, devido a própria característica desses esportes, permeados pela monotonia e repetição, bem como pela competitividade exacerbada e maior cobrança do atleta em relação aos aspectos físicos e psicológicos, ao contrário dos esportes coletivos.

Para Freire e Scaglia (2003) os jovens adolescentes apresentam grande estima e confiança com os colegas da mesma idade, cuja conversa e convivência representa um importante apoio socioafetivo durante esta fase da vida. Nesse sentido, acredita-se que as situações de convivência e ajuda presente no ambiente de treinamento coletivo do handebol, bem como a administração conjunta de desafios e suporte afetivo por parte das próprias colegas de equipe justificam a pequena probabilidade de risco das referidas atletas em desenvolver a SB.

\section{CONCLUSÃO}

Os resultados obtidos nesta pesquisa revelam que as atletas de handebol de um colégio particular do município de Ponta Grossa/PR apresentam baixa probabilidade de obter a SB pelo quesito de Exaustão Física e Emocional, pois os professores trabalham com o período de descanso de quarenta e oito horas em cada dia de treino. Em períodos de competições, aplica-se o descanso de setenta e duas horas antecedentes aos treinos normais, não acarretando no cansaço psicofísico.

No tocante a categoria de Reduzido Senso de Realização Esportiva, conclui-se que as atletas possuem uma probabilidade baixa de serem acometidas pela SB enquanto que na categoria Desvalorização Esportiva, observou-se um percentual mais elevado de risco das atletas para a o surgimento da SB, quando comparadas as demais categorias. Acredita-se que esse índice mais elevado possa estar relacionado ao fato das atletas serem reservas da equipe em competições esportivas ou pela dificuldade de conciliar as atribuições inerentes aos treinamentos desportivos com eventuais cobranças no tocante ao futuro profissional (estudos e emprego).

Com a média de todas as respostas, conclui-se que as atletas possuem um risco baixo a mediano para a presença de Burnout. Nesse sentido, sugere-se que os profissionais do movimento procurem trabalhar melhor com a valorização das atletas, com atividades que abordem a autoconfiança e valorizem o talento individual de cada indivíduo no ambiente esportivo. Por fim, observa-se a importância dos professores e treinadores estarem atentos as consequências decorrentes da SB e na eventualidade de algum atleta apresentar sintomas dessa síndrome, ressalta-se a necessidade do devido acompanhamento 
Análise de risco de Burnout em adolescentes praticantes de handebol

psicológico para realizar 0 tratamento

necessário.

\section{REFERÊNCIAS}

ALTINI NETO A.; PELLEGRINOTTI I. L.; MONTEBELO M. I. L. Efeitos de um programa de treinamento neuromuscular sobre o consumo máximo de oxigênio e salto vertical em atletas iniciantes de voleibol. Revista Brasileira de Medicina do Esporte. v. 12, n. 1, p. 33-38, 2006.

ARPINI, V. M.; VICENTINI, M. Perfil morfológico e físico de atletas de handebol masculino juvenil do colégio Castro Alves por posição de jogo: comparação com a literatura existente. Revista Ifes Ciência, v. 3, ํำ 1, 2017.

BARA FILHO, M. G.; RIBEIRO, L. S.; MIRANDA, R. O fenômeno do burnout em nadadores. Treinamento desportivo, v. 4, n. 3, p. 69-78, 1999.

BRANDÃO, M. R. F. Fatores de stress em jogadores de futebol profissional. Tese (Doutorado) Universidade Estadual de Campinas. Campinas, 2000.

CARLOTTO, M. S. A síndrome de Burnout e o trabalho docente. Psicologia em estudo, v. 7, n. 1, p. 21-29, 2002.

CHIMINAZZO, J. G. C.; MONTAGNER, P. C. Treinamento esportivo e Burnout: reflexões teóricas. Revista Digital Bueno Aires. Ano 10, n. 78., Novembro de 2004.

CUNHA, G. S.; RIBEIRO, J. L; OLIVEIRA, A. R. Sobretreinamento: teorias, diagnóstico e marcadores. Revista Brasileira de Medicina do Esporte, Niterói , v. 12, n. 5, p. 297302, Oct. 2006.

FREIRE, J. B.; SCAGLIA, A. J. Educação como prática corporal. São Paulo: Scipione, 2003.

ROCHA, F. F.; SANTOS, G. S. Síndrome de Burnout em profissionais da saúde. 2014. Disponível em: <https://www.corenmg.gov.br/documents/20143/1174580/Sindrome +de+Burnout.pdf/05f52eb25a57-f512-2e7c-571ae9a1da99?version=1.0>. Acesso em: 20 nov. 2018.

MARCONI, M. A.; LAKATOS, E. M. Metodologia Científica. 4. ed. São Paulo: Atlas, 2004.

MARQUES JUNIOR, N. K.; Periodização do treino. Educação Física em Revista, v. 6, n. 2, 2012.

NUNES, D. F. S. Sindrome de Burnout no esporte: Reflexões Teóricas. Por. MasTKD, 2009. Disponível em: < http://mastkd.com/2009/11/sindrome-de-burnout-no-esporte-reflexoes-teoricasportugues/>. Acesso em: 04 jun. 2021.

PIRES, D. A.; BRANDÃO, M. R. F.; SILVA, C. B. Validação do questionário de burnout para atletas. Revista da Educação Física da UEM, Maringá, v. 17, n. 1, p. 27-36, 2006.

PIRES, D. A.; SANTIAGO, M. L. M.; SAMULSKI, D. M.; COSTA, V. T. A síndrome de Burnout no esporte brasileiro. Revista de Educação Física da UEM, v. 23, n. 1, p. 131-139, 2012.

PIRES, D. A.; SOUZA, I. N.; CRUZ, H. R. A. Indicadores da síndrome de burnout e suas subescalas em atletas de basquetebol dos sexos masculino e feminino da seleção municipal de CastanhalPA. Revista Corpoconsciência, Santo André, vol. 14, n. 1, p. 35-48, jan/jun 2010.

RÉ, A. H. N. Crescimento, maturação e desenvolvimento na infância e adolescência: Implicações para o esporte. Motricidade, v. 7, n. 3, p. 55-67, 2011.

ROHLFS, I. C. P. M.; MARA, L. S.; LIMA, W. C.; CARVALHO, T. Relação da síndrome do excesso de treinamento com estresse, fadiga e serotonina. Revista Brasileira da Medicina do Esporte, Niterói , v. 11, n. 6, p. 367-372, Dec. 2005. 


\section{Análise de risco de Burnout em adolescentes praticantes de handebol}

RUBIO, K. O preço da glória, e do êxtase, de ser atleta. Jornal da Usp, maç, 2019. Disponível em: <https://jornal.usp.br/artigos/o-preco-da-gloria-e-do-extase-de-ser-atleta/>. Acesso em: 04 jun. 2021.

RUBIO, K. Psicologia do esporte aplicada. Casa do Psicólogo, 2003.

RUIZ, L.; EGOCHEAGA RODRÍGUEZ, J. E. Estudio del somatotipo en jugadores de balonmano por puestos y categorías. Apunts Medicina de l'esport, v. 36, n. 137, p. 25-32, 2001.

SAMULSKI, D. M. Psicologia do esporte: manual para a educação física, psicologia e fisioterapia. Manole, 2002.

SILVÉRIO, J. M. A. Burnout no desporto: estudo comparativo em atletas do triatlo, natação, ciclismo e atletismo. 1995. Dissertação de Mestrado. Universidade do Minho. Braga. Portugal, 1995.

TRIGO, T. R.; TENG, C. T.; HALLAK, J. E. C. Síndrome de burnout ou estafa profissional e os transtornos psiquiátricos. Archives of Clinical Psychiatry, v. 34, n. 5, p. 223-233, 2007.

WILMORE, J. H. Fisiologia do esporte e do exercício. Manole, 2001. 